\title{
Governing Complex Infrastructure Developments: Learning From Successful Megaprojects
}

\author{
Tim Brady ${ }^{\mathrm{a}}$ \\ Andrew Davies ${ }^{\mathrm{b}}$
}

\begin{abstract}
Past literature suggests increasing complexity in projects may be a significant factor in project failure (e.g. Morris \& Hough $^{1}$, Miller \& Lessard ${ }^{2}$, Flyvbjerg et $\mathrm{al}^{3}$, Williams ${ }^{4-5}$ ). Megaprojects - defined by Flyvbjerg et $\mathrm{al}^{3}$ as large infrastructure investments of around $\$ 1$ billion $(£ 500 \mathrm{~m})$ or more - are amongst the most complex with many suffering severe cost and time overruns. But not all mega projects fail. This paper compares two successful UK construction megaprojects, Heathrow Terminal 5 and the London 2012 Olympic Park, in terms of their complexity, and how these complexities were managed. Both projects were large and complex and subject to high levels of uncertainty, and both involved the development of unique governance structures and processes. Our analysis reveals common features but also some key differences in the approaches taken which provide lessons for the governance of future infrastructure projects and programmes.
\end{abstract}

Key words: Governance; Complexity; Megaprojects; Learning

\section{Introduction}

Over the years there has been growing academic interest in how complexity affects the management of projects and past literature has suggested that increasing complexity in projects may be a significant factor in project failure (e.g. Morris \& Hough $^{1}$; Miller \& Lessard $^{2}$; Flyvbjerg ${ }^{3}$; Williams ${ }^{4-5}$ ). Megaprojects - defined by Flyvbjerg ${ }^{3}$ as large infrastructure investments of around $\$ 1$ billion $(£ 500 \mathrm{~m})$ or more - are amongst the most complex. Cost overruns of 50\% are typical and overruns of $100 \%$ not unusual. The reconstruction of the $£ 798 \mathrm{~m}$ Wembley Stadium project, for example, was $80 \%$ over budget and delivered four years later than originally planned. But not all mega projects fail and this paper examines what are considered to be two successful UK construction megaprojects, Heathrow Terminal 5 and the London 2012 Olympic Construction Programme, in terms of their complexity, and how these complexities were addressed in the governance and management of the two megaprojects.

Both projects were large and complex and subject to high levels of uncertainty, and both involved the development of unique organisational structures and processes. However, our analysis reveals differences in the approaches taken by those responsible for the management of these projects. In the following section we briefly examine the literature on project complexity. Next we move on to our empirical material first describing our research method

\footnotetext{
a Centre for Research on Innovation Management, University of Brighton, BN2 4AT, UK

${ }^{\mathrm{b}}$ School of Construction and Project Management, University College London, WC1E 7HB, UK http://dx.doi.org/10.14453/isngi2013.proc.7
} 
- case study comparison - and how we derived the data for analysis before presenting the two cases. We analyse the two cases in terms of similarities and differences in both their complexities and the approaches taken to cope with them in the light of the literature on project complexity. We end with some brief conclusions about the results and their generalizability to other complex infrastructure project settings.

\section{What Does The Literature Say About Project Complexity?}

The inability to manage complexity has been recognised as a major factor in project failure for a number of years ${ }^{4}$. However, the concept remains ambiguous and ill-defined in much of the project management literature ${ }^{6}$. Efforts to define project complexity often make reference to systems theory and the idea that complex systems are decomposable into hierarchies of interacting components (e.g. Boulding ${ }^{7}$ and Ashby ${ }^{8}$ ). Hirschman ${ }^{9}$ was one of the first scholars to think of projects as systems, realising that the main challenge of delivering a complex project consisting of many interconnected component parts was not the size of the system itself but the difficulty in establishing a set of methods or a process to coordinate and adjust and fit the parts together into a coherent whole.

A number of scholars have used contingency theory as a way of defining project complexity. Baccarini ${ }^{10}$ proposed two dimensions - 'differentiation' and 'interdependence' to help distinguish between organisational and technological complexity. Differentiation refers to the number of components (task, specialists, and sub-components etc.) in the project system while interdependence is about the interrelatedness of the different components of the project system. Some authors have adopted the systems view to make distinctions between different types of project according to their complexity (e.g Hobday ${ }^{11}$ and Shenhar and Dvir $^{12}$ ) relating this to the complexity of the product/outcome of the project. Projects can be distinguished by dimensions of system scope and technological uncertainty.

More recently Bosch-Rekveld, Jongkind, Mooi, Bakker and Verbraeck ${ }^{13}$ have proposed a framework for characterising project complexity consisting of three main pillars technical, organizational and environmental - to categorise large engineering projects. Another recent article ${ }^{14}$ systematically reviewed the literature on project complexity to come up with a contingency framework consisting of five dimensions - structural, uncertainty, dynamics, pace and socio-political complexity project complexity. The dynamics and pace dimensions seem to add something new to the analysis of complexity. Dynamics refers to changes that might occur in the projects - which could be to specifications or goals or to the external or internal political environment - and they are broadly defined as a change in any of the other dimensions of complexity. Essentially pace refers to the rate at which the project needs to be delivered. We will see that this was an important feature in the two megaprojects we analyse below.

\section{The Research Methods}

To understand how complex megaprojects can be successfully managed, we chose a comparative case study approach. Case studies of the two projects were built up based on extensive interviews with key persons using an approach based on engaged scholarship ${ }^{15}$. Data was gathered through interviews and official documents, presentations, contracts, 
reports and the trade press. For the Heathrow T5 case interviews took place over period of 20 months from June 2005 to January 2007. The London Olympics project interviews were conducted between December 2010 and September 2011 during the final stage of construction and handover to LOCOG (the London Organising Committee of the Olympic and Paralympic Games).

\section{The T5 Project}

At the time of its execution the T5 project was one of the most complex construction projects in Europe, and the most complex and challenging project ever undertaken by Heathrow's owner BAA. All the construction work had to be carried out within a highly physically constrained environment whilst causing minimum disruption to the operational activities of one of the busiest airports in the world. The plans for T5 had been subject to the longest planning enquiry in UK history which laid down over 700 conditions including restrictions on delivery and working times. The project cost, £4.2bn, when set against its market capitalisation of around $£ 6.8$ bn in January 2006, meant that T5 was an extremely risky undertaking for BAA.

\section{A. BAA's Novel Approach to managing T5}

During the long process of preparing for T5, BAA carried out systematic case study research into every major UK construction project over $£ 1$ bn undertaken over the previous 10 years and every international airport opened over the previous 15 years and concluded that without a radically different approach the T5 project would cost over £1bn more than was affordable, would be two years late and result in six fatalities.

BAA's study identified two key areas that contributed to the poor performance of mega projects: the lack of collaboration among project partners; and, the client's reluctance to assume responsibility for project risk. BAA recognised that the risk entailed by T5 required a new approach to project management based on two core elements: integrated project teams and BAA's acceptance of the risk. These elements were used to create two documents used to manage T5: the T5 Handbook and the T5 Agreement - a novel type of cost-plus incentive contract based on the processes outlined in the T5 Handbook, which created a new set of behaviours that allowed member of projects to work under a set of collaborative rules for integrated project team working and partnering. These two elements of BAA's novel approach to project management were supported by three complementary innovations: a single digital model for project design and execution; pre-fabrication, pre-assembly and testing of components; just-in-time logistics. Together they represented a breakthrough in the management of mega projects.

\section{B. How did this approach help BAA manage complexity?}

To deal with the structural complexity BAA broke down the overall T5 project into 4 main areas: railways and tunnels, buildings, airport infrastructure and systems which went across the other three areas and involved the integration of all the IT and supporting systems. The single model environment meant that the same information was available to all parties involved thus helping with the information asymmetries that typically exist in large complex projects with multiple suppliers. The socio-political complexity in the project was addressed through the integrated project teams. These existed at the level of the 147 sub-projects and were made up of representatives from BAA and various Tier 1 suppliers: architects, designers, structural engineers, constructors, fabricators, specialist contractors etc. They were co-located, 
co-incentivised and co-responsible for the output of their projects. Where there were interdependencies between project teams these were recognised and managed at a higher level. BAA made continuous efforts to break with traditional practices by reinforcing and rewarding team-based behaviours and fostering a culture of learning amongst suppliers based on 'soft' skills such as the trust and cooperation required to work 'constructively' on the project, rather than the hard skills of traditional contracting based on the commercial estimation of risks and making claims when problems arise.

Emergent complexity was dealt with by the use of re-imbursible contracts and incentives to innovate during the project and just-in-time logistics whereby the use of 'Projectflow' software enabled teams to update daily what work had been completed so that only the materials needed for the next day's work could be lined up for delivery. Uncertainty was dealt with by earlier experimentation and standardisation of major components, by off-site testing to prove constructability and by a policy of not adopting untested technologies on site.

\section{The London Olympics Construction Programme}

The London Olympics Construction programme was large and complex. It provided most of the venues for London 2012 and consisted of over 70 individual projects with many interdependencies between them such as common services and site logistics. The programme faced a number of other challenges, the major one being the immovable deadline for the programme; the opening ceremony for the Olympics was to take place on the $27^{\text {th }} \mathrm{July}, 2012$. The organization set up around the Olympics involved multiple stakeholders (see Figure 1), some with conflicting objectives. The programme had dual objectives: delivering the venues and infrastructure for the Games and providing legacy benefits. There was a huge public sector investment in the Games and subsequently a very high public profile with the eyes of the world on the programme. These led to significant reputational risks for not only the organisations involved in the construction programme, but for the UK Government and the country as a whole. The over-riding imperative for the Olympics was that this was a programme that could not fail. It is against this background that the specific management approach was developed.

\section{A. The Approach to Managing the London 2012 Olympics Construction Programme}

The London 2012 Delivery Team consisted of the London Organising Committee of the Olympic and Paralympic Games (LOCOG) and the Olympic Delivery Authority (ODA). LOCOG was a private company responsible for the planning, funding, preparation and staging of the London 2012 games with a $£ 2$ billion budget. The ODA was a public sector body responsible for developing and building the new venues and infrastructure for London 2012 and their use afterwards. The ODA had a $£ 9.8$ billion budget.

The ODA remit was "to deliver venues, facilities, infrastructure and transport on time for the London 2012 Olympic and Paralympic Games that are fit for purpose and in a way that maximises the delivery of a sustainable legacy within the available budget". So time, quality and cost were the prime focus of the delivery but there were other 'objectives' related to broader social and economic impact: Health, safety and security; design and accessibility; equality and inclusion; legacy; employment and skills; sustainability. 


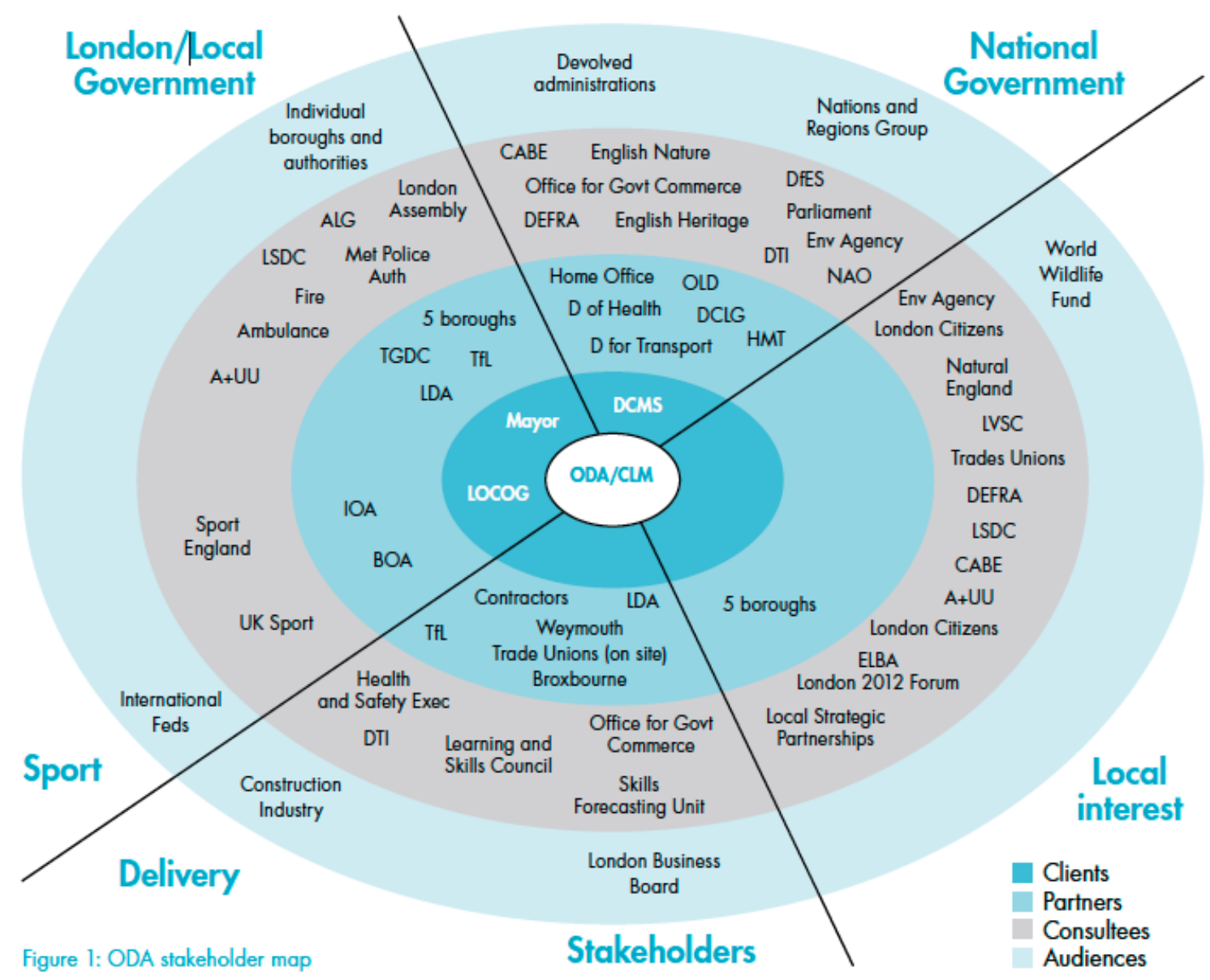

Figure 1 ODA Stakeholder Map ${ }^{16}$

The ODA programme was broken down into 50 individual projects in 6 different directorates: Infrastructure; Venues; Security; Logistics; Village; Transport. Each project had its own management structure and was led by a Tier One Contractor who was accountable for delivery. The ODA appointed a Delivery Partner, CLM (made up of a consortium of experienced construction companies: CH2MHILL, Laing O'Rourke, and Mace) to oversee the whole programme. Broadly speaking, CLM faced downwards to the various individual projects while the ODA faced upwards to the plethora of stakeholders such as LOCOG, various sports associations, many statutory bodies, and local and central Government. CLM was responsible for developing/specifying detailed project/programme management processes; administering the contracts with Tier one suppliers or equivalent; providing project assurance on each project; providing optioneering and problem solving expertise at the project level; managing the 'change' process; providing visibility of project performance for the programme level; collating performance at the programme level; managing the interfaces and dependencies between the various projects via integration management.

Some aspects -the five key management processes of up-front planning, project and programme monitoring, problem resolution, change management and integration management; the principles and targets related to health and safety and the other five priority themes; and the behaviours required to underpin the programme culture - were tightly controlled. Other aspects - how contractors would implement the principles and targets for $\mathrm{H} \& \mathrm{~S}$ and the priority themes; approaches to procurement and contract (a recognised Tier One 
contractor under design and build NEC3 C (target price with pain/gain) was adopted for the Olympic Stadium while design-led procurement was used for the Velodrome (given the desire for a 'signature' building) and a managed package strategy was adopted for the temporary venues); responses to external changes (e.g. the economic downturn in 2008 meaning the Athletes Village needed to revert to public funding) - were loosely managed to enable flexibility.

\section{B. How did this Approach Help the ODA Manage Complexity?}

The breakdown of the overall programme into individual projects helped deal with the structural complexity. The socio-political complexity was dealt with by a very strong governance structure involving multiple layers of assurance and reporting (see Figure 2). The tight-loose approach enabled the ODA to achieve a highly consistent approach across the whole programme whilst facilitating flexibility to enable emergent complexity to be managed.

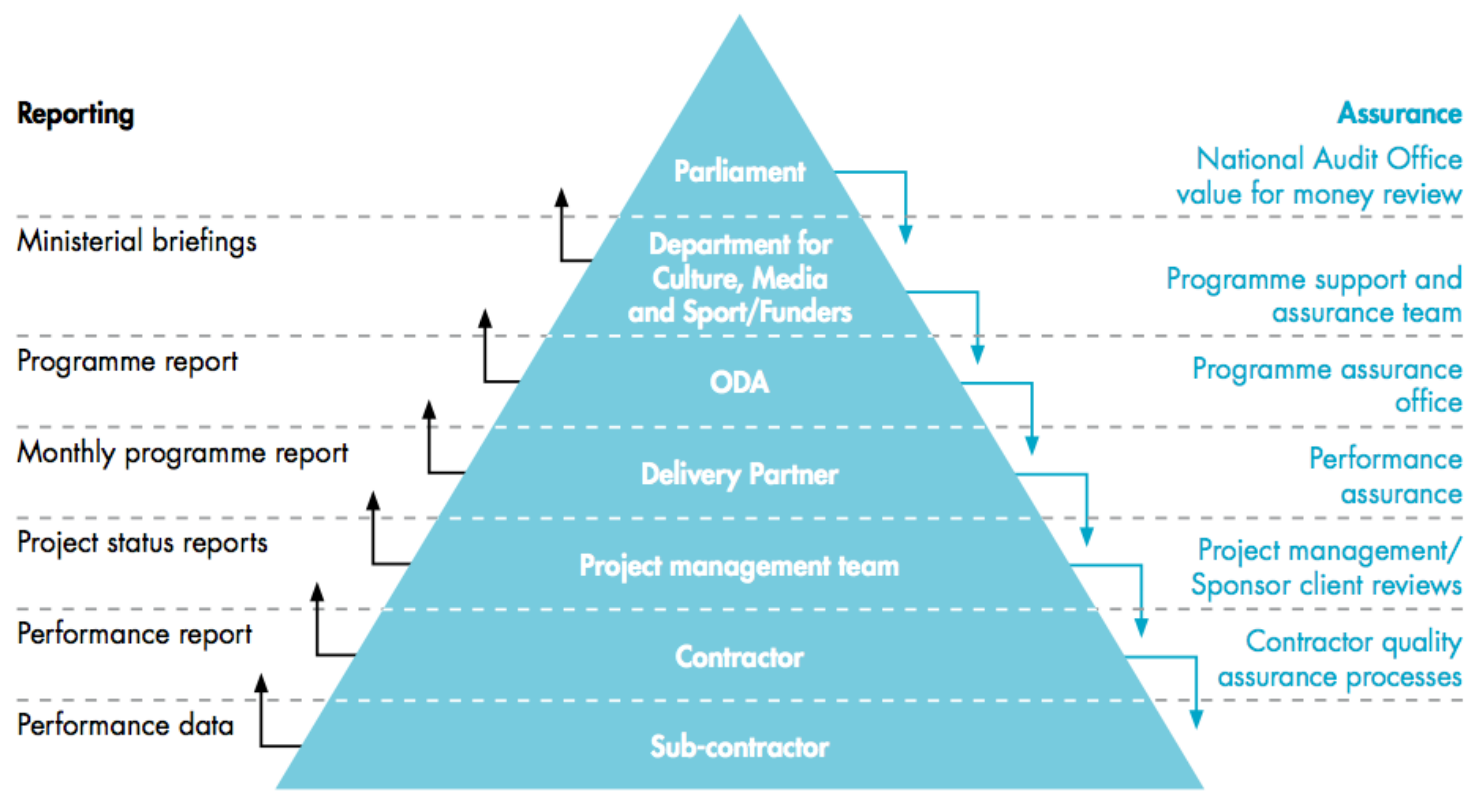

Figure 2 ODA Reporting and Assurance ${ }^{17}$

\section{Some Brief Conclusions}

While both projects were large and complex and subject to high levels of uncertainty, and both involved the development of unique organisational structures and processes there were differences in the approaches taken to govern these projects. In the T5 project, a single onesize-fits-all approach mandated by the client, BAA, established a consistent and standardised process and a common code of behaviour which was used uniformly on all sub-projects. In contrast, the ODA and its delivery partner, CLM, adopted a tight-loose approach to manage the Olympics construction programme which tried to strike a balance between consistent processes for managing change across the entire programme while adopting different approaches to individual sub-projects which allowed contractors the autonomy to adopt specific solutions to problem solving in individual projects.

In both cases time was an important factor. Both megaprojects had a long time to prepare for their openings and both had immovable end dates (for T5 this was imposed by BAA who 
insisted on an official opening date at end March 2008). Both were subject to a number of enablers which helped them be successful. In the case of T5 they were helped by the leadership of Sir John Egan who recognised that by learning from the experiences of other industries and applying these ideas, practices and technologies BAA could improve its own project processes. BAA recruited a senior team of talented people and employed leading consultants to prepare for T5 who had a deep knowledge and experience of business practices in other industries and/or a track record of successfully completing mega projects. Key enablers for the Olympics Construction Programme included existence of a well-resourced delivery partner; supportive contractual arrangements; and a supportive programme-wide culture. The division of roles between the ODA and CLM played a vital role in brokering between stakeholders and the contractors when it came to changes in requirements or changes necessitated by a project's situation. Despite this role separation, it is clear that the ODA and CLM worked very closely together - the ODA and CLM represented a "very intelligent client". Both programmes were able to depend on the best efforts of the whole workforce. In the T5 case this was partly the result of the integrated team working and the coincentivisation of suppliers but also on insistence in the T5 agreement that the best team would be made available for the project. In the case of the Olympics there was what has been described as the Olympic effect which meant that everyone was happy to be associated with the high-profile project and to seeing it succeed. Finally it should be noted that both projects had very large budgets with healthy contingency funds available for emergent needs. In conclusion we argue that the structures and processes adopted to successfully manage a megaproject should reflect the mix of complexity and uncertainty that surrounds the project.

\section{References}

${ }^{1}$ Morris, P.W.G., and G.H. Hough, The Anatomy of Major Projects, UK, John Wiley and Sons, 1987.

${ }^{2}$ Miller, R., and Lessard, D., The Strategic Management of Large Engineering Projects: Shaping Institutions, Risks, and Governance, Cambridge, Mass: The MIT Press, 2001.

${ }^{3}$ Flyvbjerg, B., Megaprojects and Risk: An Anatomy of Ambition, Cambridge: Cambridge University Press, 2003.

${ }^{4}$ Williams, T.M., "The need for new paradigms of complex projects", International Journal of Project Management, Vol. 17, No. 5, 1999, pp. 269-273. http://dx.doi.org/10.1016/S0263-7863(98)00047-7

${ }^{5}$ Williams T. M., "Assessing and moving on from the dominant project management discourse in the light of project overruns", IEEE Transactions on Engineering Management Vol. 52, Iss. 4, 2005, pp. 497-508. http://dx.doi.org/10.1109/TEM.2005.856572

${ }^{6}$ Geraldi, J., "Patterns of complexity: The thermometer of complexity", Project Perspectives 2008, The Annual Publication of International Project Management Association, 2008, pp. 4-9

${ }^{7}$ Boulding, K.E., 'General systems theory - the skeleton of science', Management Science, Vol. 3, No. 2, pp. 197-208.

${ }^{8}$ Ashby, W.R., Introduction to cybernetics, Chichester: John Wiley \& Sons.

${ }^{9}$ Hirschman, A.O., Development projects observed, Washington: The Brookings Institution, 1956.

${ }^{10}$ Baccarini, D.,The concept of project complexity - a review“, International Journal of Project Management, Vol. 14, No. 4, 1996, pp. 201-204. http://dx.doi.org/10.1016/02637863(95)00093-3 
${ }^{11}$ Hobday, M., "Product complexity, innovation and industrial organisation", Research Policy, Vol. 26, No. 6, 1998, pp. 689-710. http://dx.doi.org/10.1016/S0048-7333(97)00044-9

${ }^{12}$ Shenhar, A. J., and Dvir, D., "Toward a typological theory of project management", Research Policy, Vol. 25, No. 4, 1996, pp. 607-632. http://dx.doi.org/10.1016/00487333(95)00877-2

${ }^{13}$ Bosch-Rekveld, M., Jongkind Y., Mooi H., Bakker H., and Verbraeck, A., "Grasping project complexity in large engineering projects: The TOE (Technical, Organizational and Environmental) framework", International Journal of Project Management, Vol. 29, 2011, pp. 728-739. http://dx.doi.org/10.1016/j.ijproman.2010.07.008

${ }^{14}$ Geraldi, J., Maylor, H., and Williams, T., "Now, let's make it really complex (complicated): A systematic review of the complexities of projects", International Journal of Operations \& Production Management, Vol. 31, Iss. 9, 2011, pp. 966 - 990. http://dx.doi.org/10.1108/01443571111165848

${ }^{15}$ Van de Ven, A., Engaged scholarship: a guide to organizational and social research. Oxford: Oxford University Press, 2007.

${ }^{16}$ Olympic Delivery Authority, ODA Stakeholder Map, 2012. Retrieved from http://learninglegacy.independent.gov.uk

${ }^{17}$ Olympic Delivery Authority, ODA Reporting and Assurance, 2012. Retrieved from http://learninglegacy.independent.gov.uk 